\title{
University access for disadvantaged children: A comparison across countries
}

\author{
John Jerrim (Institute of Education, University of London) \\ Anna Vignoles (University of Cambridge) \\ January 2015
}

\begin{abstract}
In this paper we consider whether certain countries are particularly adept (or particularly poor) at getting children from disadvantaged homes to study for a bachelor's degree. A series of university access models are estimated for four English speaking countries (England, Canada, Australia and the United States) which include controls for comparable measures of academic achievement at age 15 . Our results suggest that socio-economic differences in university access are more pronounced in England and Canada than Australia and the United States, and that crossnational variation in the socio-economic gap remains even once we take account of differences in academic achievement. We discuss the implications of our findings for the creation of more socially mobile societies.
\end{abstract}

Key Words: University access, educational inequality, social mobility, PISA

JEL codes: I20, I21, I28.

Contact Details: John Jerrim (J.Jerrim@ioe.ac.uk) Department of Quantitative Social Science, Institute of Education, University of London, 20 Bedford Way London, WC1H 0AL Acknowledgements: Jerrim has been partly funded by the British Academy and the ESRC. He also wishes to acknowledge the invaluable support of the PATHWAYS postdoctoral programme. Vignoles time has been partly funded by the Nuffield Foundation. Helpful comments have been received from participants at the Sutton Trust social mobility summit, the 2012 IWAAE conference, 2012 LLAKES conference and seminars at the Institute of Education and Michigan State University. Particular thanks go to Stephen Childs for research assistance with the YITS data and to Barbara Schneider for facilitating Jerrim's visit to MSU. 


\section{Introduction}

Within a number of countries, higher education offers substantial monetary and nonmonetary rewards (Black 2009; Chevalier and Conlon 2003). For instance, young people who obtain a tertiary qualification tend to have higher pay, hold more prestigious occupations and have better health than those who do not (Groot and van den Brink 2006). However, individuals from low income and low parental education backgrounds are disproportionately underrepresented within the undergraduate population, particularly within elite higher education institutions. Previous research (Carneiro and Heckman 2002) has shown that the substantial gaps in university attendance by parental income observed in the United States can be largely explained by differences in the prior academic achievement of rich and poor young people in high school. Gaps in university participation by parental education level in contrast are only partly attenuated by allowing for differences in the prior achievement of students. We ask whether this striking finding holds in other institutional contexts, where university tuition costs, financial support packages and application processes are rather different. We attempt to answer this question by examining the link between parental education, household income, academic achievement and university attendance across Australia, Canada, England and the United States (Appendix A provides key information about these countries).

Haveman and Wolfe (1995) illustrate how parental education and household income influence university entry - see Figure 1. In stage 1 parental education has a direct influence on the investments made in children; more educated parents are, for instance, more likely to read to their children. Parental education also has an indirect influence on children's development through household income (e.g. educated parents earn more and provide their children with more educational resources). These parental investments create large socioeconomic differences in cognitive ability on entry into school. Parental education directly, and indirectly via family income, interacts with school quality and peers, widening socioeconomic differences in achievement by the mid-teenage years. Young people then decide whether to enter university (stage 2). Socio-economic gaps in university access will emerge due to (i) disadvantaged children's weaker academic preparation and (ii) other non-academic constraints (e.g. credit constraints, risk aversion, lack of information or aspiration). Both these factors will be affected by parents' education and income. Young people then enter the labour market in stage 3 . 


\section{Figure 1}

Access to university thus differs across parental education and income groups due to:

(i) Differences in school achievement;

(ii) Constraints upon choices (e.g. credit constraints, financial support, risk aversion);

(iii) Other non-academic factors (e.g. students' aspirations, a lack of information about the costs and benefits of higher education).

Yet the extent to which (i) can explain socio-economic differences in university admission is controversial. Leading economists (Cunha et al 2006) have recently argued that inequality in university access largely reflects differences in high school achievement (Cameron and Heckman 2001, Chowdry et al. 2012, Ermisch and Del Bono 2012) and that other factors are less important. However, much sociological work continues to stress the importance of factors other than scholastic attainment in university access, including expectations and aspirations, family and social norms, and subjective beliefs regarding chances of successful graduation (Jackson 2013). The resolution of this debate seems to hinge upon one key question - to what extent can family background differences in university access be explained by differences in prior achievement?

Evidence on this matter is mixed. Ermisch and Del Bono (2012) state there is 'virtually no relationship' between parental education and university access in England once age 16 academic achievement is controlled. This is supported by Chowdry et al. (2012) who, albeit with a relatively crude measure of socio-economic background (eligibility for state benefits that provide Free School Meals), similarly find little relationship between socioeconomic background and university participation conditional on prior achievement. In contrast, Jackson et al (2007) suggest that up to half the socio-economic gap in teenagers' educational decisions in England is due to factors other than academic ability. In the US, Cameron and Heckman (2001) and Carneiro and Heckman (2002) find prior academic achievement to be a greater barrier to disadvantaged children's prospects of entering university than parental income. However, Belley and Lochner (2007) argue that family income has become a much more important factor in recent years. Using Canadian data, Finnie and Mueller (2008) find that high school grades can account for half of the association 
observed between parental education and university participation - yet the 'effect' of family income on participation remains unchanged even after allowing for prior achievement. In Australia, Le and Miller (2005) argue that 'equity-based scholarships or university fee rebates [need] to be provided to Year 12 graduates' to address socio-economic differences in university education, implying a role for family income in explaining university participation. By contrast, Cardak and Ryan (2009) show that, conditional upon school achievement, disadvantaged Australian students are just as likely to attend university as their more fortunate peers.

The aim of this paper is to thus provide comparable evidence on the link between parental education, household income, academic achievement and university entrance for Australia, Canada, England and the US. These countries have been chosen because, although they share a number of similarities (e.g. language, level of economic development and political systems) they differ in a number of important ways with regards their higher education system (e.g. level of tuition fees, application process, the role of the private sector). We begin by investigating the 'raw' parental education gap in university access, before investigating the extent to which these gaps can be explained by prior academic achievement (point (i) above). This enables us to establish whether parental education is still associated with university entry, even amongst young people who are equally well qualified to attend.

Section 2 summarises the higher education systems across the countries considered. Data and methods are described in section 3, with results in section 4, and conclusions in section 5 .

\section{University systems}

The cohorts we consider in this paper were first eligible to enter university in 2003 in Canada, 2004 in the United States, 2006 in Australia and 2008 in England. Key indicators of the university systems are presented in Table 1. Young people in the different countries face different non-academic constraints to entry. One obvious example is cost. Partly due to its large private sector, during this period annual tuition costs were almost three times higher in the United States $(\$ 11,605)$ than England $(\$ 4,731)$, Canada $(\$ 3,774)$ and Australia $(\$ 4,369)^{1}$. Moreover, bachelor's degrees take longer to complete in the US (typically four years) than in some other countries (e.g. three years in England), increasing total tuition fees and

\footnotetext{
${ }^{1}$ Note that figures for England refer to the period before the 2012 reforms - with tuition fees now substantially higher.
} 
opportunity costs. The countries also differ in the level of state financial support, and thus their ability to limit the role of credit constraints and risk aversion for poorer students. A complex system of financial aid operates in Canada, where there is an 'intricate web of both Federal and provincial / territorial programs' offering student support, with universities and colleges also involved (Berger et al 2008). There is also a system of non-need based aid, where the Canadian government provides students with educational tax credits and saving plans (Berger et al provide further information). The proportion of the population receiving (non-repayable) scholarships and grants is greatest in the US (65\% - see Table 1). But public loans that are repaid on an income contingent basis are provided in England and Australia, which offsets risks associated with human capital investment (Chapman and Ryan 2005). For instance, in Australia the public loan covers upfront costs, with graduates paying back a percentage of their earnings over a certain threshold (this was somewhere between $4 \%$ and $8 \%$ on earnings over approximately $\$$ US 47,000 in 2010). Scholarships, means-tested bursaries and grants also have a significant role in each country, with more than half of students receiving such aid in England and the United States (see Table 1).

\section{Table 1}

School - to - university transitions also differ. In England, compulsory education for the cohort we consider ended at age 16. Those aiming for university continue full time education for a further two years, with university offers based largely upon predicted grades in national examinations. The supply of university places for the English cohort that we consider in this paper was constrained, with a limited number of places available in different higher education institutions. There is, in contrast, a single educational transition point in Canada and the United States (at age 18), with a well-developed two-tier tertiary education system (made up of two and four year degrees). In Australia, the compulsory school leaving age varies by state/territory and the university admission process is also generally centralised at state or territory level, with entry determined by school grades ('ENTER' scores).

\section{Data}

Four nationally representative longitudinal datasets are analysed:

The Longitudinal Study of Australian Youth (LSAY 2003 - Australia)

The Youth in Transition Study Cohort A (YITS 2000 - Canada) 
The Longitudinal Study of Young People in England (LSYPE 2004 - England)

The Educational Longitudinal Study (ELS 2002 - United States)

These data have a high degree of cross-national comparability. In particular, each study has been designed to be nationally representative, and all follow children from the mid-teenage years (around age 15) through to at least early adulthood (age 20). All four datasets also contain detailed information on parental education and measures of the student's educational attainment, the latter being based upon tests taken at similar ages. Finally, each has captured information on young people's university entrance, including data on the precise institution they attend. These four studies thus represent the best data available to compare higher education access across countries.

\subsection{Sample design}

The Canadian and Australian datasets are longitudinal follow-ups of the Programme for International Student Assessment (PISA) 2000 or 2003 cohort. ELS (United States) began by interviewing a cohort of 16 year olds in 2002, with longitudinal follow-ups at ages 18 and 20. The LSYPE (England) surveyed 14 year olds in 2004 with annual follow-ups until age 20. (Note that the data for England refer to a cohort of young people entering university before the widespread changes to the higher education finance system in 2012). In each study, schools were the primary sampling unit and pupils randomly chosen within them ${ }^{2} .78 \%$ (US), 64\% (Australia), 55\% (Canada) and 55\% (England) of respondents remain in the study at age 20. Response weights are applied to account for non-response. Sample sizes are 12,575 (US), 9,446 (Canada), 7,715 (England) and 6,536 (Australia).

\subsection{Family background}

Our preferred family background measure is highest level of parental education. This is a key determinant of household financial resources, and the time and goods parents invest in their offspring - see Figure 1. It is also widely used in other cross-national comparative studies of social inequality (Smeeding et al 2011, Ermisch et al 2012). International Standard Classification of Education (ISCED) categories are used to define parental education groups. Although these have been designed to enhance cross-national comparability, national qualifications do not always fit easily into this framework. We thus aggregate ISCED levels

\footnotetext{
${ }^{2}$ Huber-White adjustments or school fixed effects are used to account for clustering.
} 
into three broad groups (see Appendix B) as previously used in academic and public policy research (e.g. Ermisch and Del Bono 2012, OECD 2012):

$$
\begin{array}{ll}
\text { 'Low' education }=\text { ISCED } 0-2 & \text { [e.g. less than high school }] \\
\text { 'Medium' education }=\text { ISCED 3 }-5 b & \text { [e.g. high school to associate degree] } \\
\text { 'High' education }=\text { ISCED 5a/6 } & \text { [e.g. bachelor's degree and higher]. }
\end{array}
$$

Descriptive statistics are presented in Table 2, including the distribution of parental education. The spread of respondents across ISCED levels is quite similar across countries, though with fewer individuals in the top category in England and Canada than Australia and the US.

\section{Table 2}

\section{$\underline{3.3 \text { Academic achievement }}$}

Each dataset contains information on respondents' academic achievement at age 18. The measures available for each country are reported in Table 3. In England A-Level grades (and vocational equivalent qualifications) and Key Stage 5 total points are used. Grade Point Average (GPA), the number of Carnegie units taken and SAT quintile are used in the United States, along with performance on a maths test ELS cohort members sat at age 18. GPA in reading, maths and an average for other subjects is used for Canada, while Tertiary Entry Rank (a percentile ranking of individuals) and high school graduation status are available in Australia.

Controlling for these age 18 academic attainment measures would eliminate prior achievement as an explanation as to why university access differs between parental education groups. However, these variables are also potentially endogenous; attainment measured at age 18 may be influenced by decisions regarding likely higher education participation made at an earlier age. Alternatively, one could control for children's test scores at a younger age (e.g. age 15) before young people are making decisions about university ${ }^{3}$. This may reduce concerns over possible endogeneity, but comes at the cost of family background potentially

\footnotetext{
${ }^{3}$ Of course one might argue that students will apply effort differentially even before age 16 depending on whether they intend to go to university. We cannot overcome this problem.
} 
having an (unmeasured) additional influence upon achievement beyond age 15. As both approaches have strengths and weaknesses, we estimate a series of university access models controlling for prior achievement measured at (i) just age 15 and (ii) measured at both age 15 and age 18 (see section 3.5).

We attempt to measure test scores at age 15 in a consistent way by using measures based upon the OECD's PISA framework ${ }^{4}$. All Canadian and Australian respondents completed the PISA test. American children sat reading and maths tests which, critically, included some PISA questions. The survey organisers have thus estimated PISA test scores for the ELS cohort using equipercentile equating (Ingels et al 2005: 37-41). English and maths test scores are also available in the LSYPE (England), but refer to performance on tests taken by this cohort at age 14 (key stage 3 tests). However, Micklewright and Schnepf (2006) and Micklewright et al (2010 / 2012) show that the correlation between these key stage 3 national exam and PISA test scores in England is high (e.g. 0.70 for reading and almost 0.85 for maths) and provide detailed regression models illustrating how they map on to one another. We use results from Micklewright and Schnepf (2006) and Micklewright et al (2012) to produce PISA achievement measures for England comparable to those from other countries (full details are available from the authors upon request) $)^{5}$. Unfortunately this is only possible for state school pupils (93\% of the LSYPE sample) $)^{6}$. However, robustness tests suggest this is unlikely to have a major influence upon our substantive conclusions ${ }^{7}$.

Table 3

\section{$\underline{3.4 \text { Bachelor's degree }}$}

Anyone enrolled in a bachelor's degree up to age 20 is defined as a university entrant (this excludes associate degrees in the US and foundation degrees in England $)^{8}$. We are conscious that participation at older ages and graduation rates vary across countries, which we cannot

\footnotetext{
${ }^{4}$ Of course, PISA scores also have limitations, including less than perfect reliability, as discussed by Jerrim (2013).

${ }^{5}$ Substantive findings remain intact if (observed) Key Stage 3 scores are used in place of (estimated) PISA scores. As PISA scores for England are estimated, we have investigated the sensitivity of the estimated standard errors using (i) analytic methods; (ii) bootstrapping (iii) observed key stage 3 test scores in place of the PISA estimates, and find little change to our results.

${ }^{6}$ Canada, Australia and the US include state and private school pupils.

${ }^{7}$ Specifically, we estimate test scores for private school children via imputation. The high SES parameter estimates increase by approximately 0.10 standard deviations.

${ }^{8}$ Some two-year college students may complete a four year degree, though upgrade rates remain low (Long and Kurlaender 2009). Exclusion of these students means we may be slightly understating low SES HE participation rates in the US (as this group is the most likely to enrol in an associate degree).
} 
allow for in our work. In Appendix $\mathrm{C}$ we provide additional analysis focusing on entry into 'selective' universities only, with little substantive change to our results.

\section{$\underline{3.5 \text { Model specification }}$}

We estimate a series of logistic regression models for entry into university ${ }^{9}$ :

$\log \left(\frac{\pi\left(E_{i j}\right)}{1-\pi\left(E_{i j}\right)}\right)=\alpha+\beta \cdot S_{i}+\gamma \cdot P_{i}+\delta \cdot G_{i}+\varphi \cdot C_{i}+\mu_{j} \quad \forall \mathrm{k}$

Where:

$\Pi\left(E_{i j}\right)=$ Probability of enrolment $\mathrm{j}(\mathrm{E}=1$ enrol, $\mathrm{E}=0$ otherwise $)$

$\mathrm{S}=$ Parental education dummy variables (reference: ISCED level $3-5 b$ ).

$\mathrm{P}=$ Age 15 (PISA or equivalent) test scores

$\mathrm{C}=$ Control variables (gender and language spoken at home)

$\mathrm{G}=$ Age 18 academic achievement

$\mu_{j}=$ School fixed effects

$\mathrm{i}=$ Child $\mathrm{i}$

$\mathrm{j}=$ School $\mathrm{j}$

$\mathrm{k}=$ Country $\mathrm{k}$

Four specifications are estimated. Only parental education and basic controls are included in specification 1. Estimates of $\beta$ will thus capture all channels by which parental education influences university attendance. PISA scores are added in specification 2 , with $\beta$

\footnotetext{
${ }^{9}$ We have experimented with models including controls for respondents' month and year of birth, and found very little change to the results presented (and substantive conclusions drawn). Similarly, we have also reestimated models including controls for family structure and number of siblings. In the baseline (unconditional) estimates, this reduces the SES gap in university access by about 10 percent in England and the United States, with little change in Australia (data not available for Canada).
} 
now reflecting differences by parental education group in university participation that remain after allowing for differences in age 15 test scores. Specification 3 includes school fixed effects, revealing whether school-level factors explain any of the remaining parental education gap in university attendance, above and beyond schools' possible influence upon young people's test scores. This might include differences across schools in information provided about post-secondary education and peer effects. Finally specification 4 restricts the sample to only young people still in education at age 18, and includes all academic achievement controls ${ }^{10}$.

All estimates are presented as differences in log-odds. This is a linear metric which can take any value along the real number line, with larger absolute values indicating a stronger association. Negative values indicate the outcome is less likely to occur relative to the reference group, while positive values suggest the outcome is more likely to occur. Logodds are more attractive than alternatives like marginal effects (predicted probabilities) as they are not sensitive to the point on the logistic distribution at which they are estimated, and are not influenced by differences between countries in the absolute proportion of children who enter university. However, appreciating this metric is cumbersome to interpret, we also present predicted probabilities in the text to aid interpretation. These are based upon estimates from linear probability models following the same specification as presented above.

\section{Results}

This section summarises our main findings, with full parameter estimates available from the authors upon request. Figure 2 illustrates the parental education gap in university access. The light grey segments of the bars illustrate differences between the low (ISCED 0 - 2) and middle (ISCED 3 - 5b) parental education groups. The dark grey segments refer to the middle parental education - high parental education (ISCED 5A/6) comparison.

\section{Figure 2}

Figure 2 Panel A includes only gender and immigrant status as controls. The difference in university participation between the low and middle parental education groups is substantial and statistically significant in Canada (1.16 log - odds or 20 percentage points),

\footnotetext{
${ }^{10}$ PISA scores at age 15 are included but school fixed effects are removed.
} 
England and the United States (approximately 0.85 log-odds or 15 percentage points).

Interestingly, the gap is significantly smaller (at the $1 \%$ level) in Australia ( $0.36 \mathrm{log}-$ odds or 7 percentage points).

Turning to the middle - high parental education comparison, differences are substantial (always more than $1.0 \log$ odd) and significantly different from 0 at the $1 \%$ level. The gap is particularly big in England (1.50 log odds), meaning children with highly educated parents are approximately four and a half times more likely to enter university than their peers whose parents have an average education level. The analogous figures are approximately $1.3 \log$ - odds in Canada and the US, and $1.14 \log$-odds in Australia (which is significantly different at the 5\% level to England and the US). Bringing these results together, the overall difference between the high and low parental education groups is notably bigger in Canada (2.53 log - odds) and England (2.36 log - odds) than the US (2.19 log - odds) and, particularly, Australia (1.51 log - odds).

Panel B controls for PISA test scores. The previous substantial difference between the low and middle parental education groups has been greatly reduced in England and the US (from approximately $0.85 \log$ - odds to 0.30 and 0.41 respectively), modestly in Canada (from 1.16 to $0.86 \log$ - odds), but with virtually no change in Australia (0.36 log - odds in specification 1 to 0.35 in specification 2). Although the difference between the low and middle groups always remains statistically significant, the magnitude becomes small (roughly 5 percentage points) except in Canada (where the gap remains around 20 percentage points). Thus the reason why children with uneducated parents are less likely to go to university than a child with averagely educated parents is largely due to differences in prior attainment (before age 15). Moreover, differences in age 15 test scores explain most of the cross-national variation observed in previous estimates. Thus university participation amongst the low and middle parental education groups is more equal in Australia than in England and the US due to factors taking hold before age 15 and not differences in how tertiary education systems are designed. This has important implications for public policy; enhancing academic achievement in school is vital if we are to raise university participation rates amongst disadvantaged children. Redesigning the higher education system alone (e.g. tuition fees, financial support) is unlikely to be enough.

The middle - high parental education gap also declines once PISA scores are added, falling from 1.51 to $0.96 \log$ - odds in England, 1.37 to 1.10 in Canada, 1.33 to 1.00 in the US, and 1.14 to 0.75 in Australia. Age 15 achievement thus accounts for one third of the difference in university participation between these groups in England and Australia, and 
around a quarter in Canada and the US. Yet large parental education gaps (and cross-national variation) remain. For instance, the high parental education group in England, Canada and the US are still two and a half to three times as likely to enter university as the middle group (and roughly twice as likely in Australia). Again, this has important implications. First, high rates of university access amongst children with highly educated parents cannot solely be attributed to their superior test scores at age 15, as measured by PISA style assessments. Second, those with highly educated parents are significantly more likely to enter university than both the middle and low groups. This implies policies should aim to increase university participation amongst both low and middle SES children, rather than focusing upon the most disadvantaged group alone.

School fixed effects are included in Figure 2 Panel C. Interestingly, the key parameters hardly change. The middle - high parental education gap declines by just $0.04 \mathrm{log}$ - odds in England, 0.08 in the United States, and only slightly more in Canada (0.18 logodds) and Australia (0.13 log-odds). This suggests that schools currently play a minor role in explaining parental education differences in university access (net of their influence upon age 15 test scores). This is a powerful result. It suggests that even when children attend the same school and have similar levels of achievement at age 15, those from the middle parental education group are still less likely to go to university than those from a high parental education background. Hence the parental education gap in degree enrolment is not simply caused by poorer students attending lower quality schools or schools that do not help their students apply to go to university. The implication of this finding is also, for example, that school peer effects do not seem to be an important factor in university access beyond their possible influence upon age 15 achievement.

In specification 4 the sample is restricted to those eligible to enter university, with a wide range of academic achievement scores up to age 18 added to the model. The difference between the bottom and middle groups is no longer statistically significant at conventional thresholds (in any country other than Canada). This supports our claim that, in three of the countries, low school achievement is the primary reason why children from low parental education backgrounds are relatively unlikely to enter university. The middle - high parental education gap is also smaller once we allow for age 18 achievement measures, and it is reduced by more in some countries than in others. For instance, compared to panel B, the high parental education parameter estimate is reduced by roughly 5\% in Canada, $35 \%$ in Australia, 25\% in the United States and by approximately 50\% in England (from 0.96 to 0.46 $\log$ odds). This is perhaps unsurprising given that, for this cohort, compulsory education in 
England ended at age 16 (and that we have now restricted the sample to only those individuals still in education at age 18). Therefore the raw parental education gaps in university participation are larger in England initially, but once we allow for entry qualification at age 18, they are reduced to a more modest level. One could argue that the English system is more meritocratic since one's achievement and qualification level at age 18 is the main driver of university participation. Alternatively one could make the point that parental education differences in university participation are larger in England because the education system gets increasingly selective even before university entry.

\section{The role of family income}

In Figure 1 we suggested that parental education and family income have independent influences on children's development and chances of entering university. Ideally, both parental education and family income would therefore have been included in our empirical model. Unfortunately, the parental income data available in each dataset are of variable quality, and not necessarily comparable across countries. We have therefore estimated a reduced-form of the theoretical model presented in Figure 1, with parental education capturing both the direct effect of a child having a more educated parent, and the indirect effect of being raised in a higher income household.

However, in a set of additional analyses, we have investigated whether household income mediates the relationship between parental education and university participation once academic attainment has been controlled. The intention of this additional analysis was to establish whether family income (and low family income in particular) had an independent association with university participation, and whether broadly similar results in this regard were found for all four countries. Specifically, following Cunha et al (2006), we hypothesised that there would be a strong unconditional association between low income and university access, but that this would weaken substantially once parental education and cognitive test scores were controlled. All these additional analyses, and a full description of the income data available, are available from the authors upon request.

Our results can be summarised as follows. In all four countries we found a strong unconditional association between household income and access to university. However, this association was substantially reduced as controls for parental education and PISA scores were added, with the impact of low family income falling in all four countries by at least 70 percent. Moreover, once grades at age 18 were added, the impact of low household income 
was statistically indistinguishable from 0 in each of the four countries at conventional thresholds.

We therefore found striking similarities across countries (despite the different income measures used). Low family resources may be associated with university attendance - but generally via its influence upon test scores and academic achievement up to age 15 . We are however mindful that the income measure is not high quality in all cases and this may depress its apparent effect upon university participation. In contrast, parental education still had a strong independent association with university participation, even after parental income and prior school achievement were controlled.

\section{Conclusions}

This paper has considered how the link between parental education, household income, secondary school achievement and access to university compares across Australia, Canada, England and the United States. Our evidence can inform the debate about whether improving the achievement of more disadvantaged children in the school system should be a priority, rather than admission reform at the point of entry into tertiary education. A key strength of the paper is that we have used surveys and measures of prior achievement that have a high degree of comparability across countries.

Parental education gaps in university participation are large, and of broadly similar magnitude, in each of the four countries. This may be somewhat surprising, given their rather different institutional arrangements for access to and funding of tertiary education. We also find little evidence that family background differences in university entry are substantially larger in the particular countries with high private costs of university, such as the United States. These findings hint at factors outside the university system being responsible for these findings.

We also find strong evidence that secondary school achievement is a key mediator linking parental education, family income and access to university in all four countries. In particular, our results indicate that the influence of low parental income is statistically insignificant once academic achievement in secondary school is controlled. This is in-line with previous evidence from Australia (e.g. Cardak and Ryan 2009), Canada (e.g. Finnie and Mueller 2008) and the United States (e.g. Carneiro and Heckman 2002). This is also consistent with UK evidence from Chowdry et al. (2012), who examine this issue using administrative (population) data from the education system and an income based measure of 
socio-economic status ${ }^{11}$. Specifically, they too find only a very small socio-economic gap remains after controlling for pupil achievement at age 16 (GCSE test scores).

Our work does however also indicate a sizeable and statistically significant difference in university participation by parental education group, which remains even after controlling for test scores at age 14/15. This implies that, even if parental income mediates through pupil achievement, there appears to be an independent role of parental education in influencing university participation (including the other family attributes that this may proxy, such as parental attitudes and aspirations). This finding is not necessarily inconsistent with previous UK studies which have suggested little role for family background in explaining university participation after controlling for student achievement at 16 and 18 (e.g. Marcenaro-Gutierrez et al 2007; Chowdry et al 2013). In fact, we too find a very strong unconditional association between family background and university access (1.23 log-odds), which becomes small and statistically insignificant once age 18 attainment has been controlled ( 0.14 log-odds). This is as per the work Chowdry et al (whose study has the advantage of an extremely large sample size). Hence our study suggests that parental education has a particular role to play in explaining students' progression between age 14/15 and high school graduation or equivalent at age 18: the socio-economic gap appears to widen during this critical period.

In any case some caution should be exercised in comparing our analysis with this previous evidence from the UK. These previous studies either refer to a much earlier cohort of young people (those entering university in the mid 1990's in Marcenaro-Gutierrez et al 2007) or only include limited measures of family background and specifically no information on parental education. Additionally, with respect to Marcenaro-Gutierrez et al 2007, the stronger residual impact of parental education that we find could be due not just to the different age of test score data, but also to an increasing influence of family background over time. This in turn could be linked to major changes in the higher education system in England between the 1990s (the cohort they studied) and late 2000s (the cohort we have studied); between these time-points university tuition fees were introduced (and subsequently increased) along with the system of financial support (e.g. less use of non-repayable student grants and a greater reliance upon income-contingent loans) ${ }^{12}$. Given that our data do not go back far enough, we are unable to say more about this issue.

\footnotetext{
${ }^{11}$ Chowdry et al use an income based measure that is an amalgam of pupil's eligibility for Free School Meals (which in turn is linked to their family being in receipt of different types of welfare) and the affluence of the neighbourhood in which the child lives.

12 This is under the assumption that parental education is a better measure of family background than those used in the study by Chowdry et al.
} 
We therefore conclude that conditional on achievement in early secondary school, parental education, as a long run indicator of socio-economic differences between families, strongly predicts university participation. In contrast, the correlation between university access and shorter run indicators of family circumstances, such as parental income, is notably weaker. This finding, which holds across different national settings, suggests that, at current levels of cost, it is not directly financial barriers that drive the low university participation rates of students from poorer backgrounds. This is consistent with the seminal work of Cunha et al (2006), who argue that inadequate investments made throughout childhood, rather than costs and credit constraints at the point of entry, are primarily responsible for disadvantaged children's low levels of university participation. We do have to acknowledge, however, the potential problem that income is measured poorly in some studies, thus potentially depressing its effect in the model.

More generally, it is important to make clear the limitations of this work and the need for future research. First, the higher education systems in some of the countries considered have seen significant change since the time these data were collected. For instance, all results for England refer to a cohort of young people who entered university before the tripling of tuition fees from $£ 3,000$ to $£ 9,000$ per annum (along with a number of other changes to student finance and support). An interesting question is therefore whether the patterns found will continue to be observed in future studies. Second, although we have harmonised the data analysed across these four countries, this was done ex-post (i.e. after data collection). A systematic attempt to collect rich, comparable data across a large number of higher education systems is the next important step in this line of research - a gap that we hope the OECD's forthcoming Assessment of Higher Education Learning Outcomes (AHELO) study will be able to fill. Finally, although we have attempted to measure how the socio-economic gradient in university access differs across four countries, our ability to link this to particular features of the higher education systems has been limited. This is due to the small number of countries with such high quality, longitudinal data available. Nevertheless, establishing the link between the socio-economic gradient in university access and macro-level factors such as the level of tuition fees and financial support available to students is an important direction for future work.

So, in conclusion, these findings have two important implications for public policy. First, as we find substantial differences between the high and middle/low parental education groups, interventions should seek to increase university participation rates amongst young people from both low and middle socio-economic backgrounds, rather than focusing 
exclusively upon those from the most disadvantaged homes. Second, the key role of prior achievement suggests that initiatives designed to boost school performance (rather than lowering higher education tuition fees) will be pivotal in reducing socio-economic inequality in university participation, particularly in England and the United States.

\section{References}

Belley, P. and Lochner, L. (2007) 'The Changing Role of Family Income and Ability in Determining Educational Achievement', Journal of Human Capital, 1(1): 37 - 89.

Berger, J.; Motte, A. and Parkin, A. (2008) 'The Price of Knowledge: Access and Student Finance in Canada', The Canada Millennium Scholarship Foundation.

Black, D. (2006) 'Estimating the Returns to College Quality with Multiple Proxies for Quality', Journal of Labor Economics, 24(3): 701 - 728.

Cameron, S. and Heckman, J. (2001) 'The Dynamics of Educational Attainment for Black, Hispanic, and White Males', Journal of Political Economy, 109(3): 455 - 499.

Cardak, B. and Ryan, C. (2009) 'Participation in Higher Education in Australia: Equity and Access', The Economic Record, 85(271), 433 - 448.

Carneiro, P. and Heckman, J. (2002) 'The Evidence on Credit Constraints in Post-Secondary Schooling', Economic Journal, 112(482): 705 - 734.

Chapman, B. and Ryan, C. (2005) 'The Access Implications of Income Contingent Charges for Higher Education: Lessons from Australia', Economics of Education Review, 24(5): 491 512.

Chevalier, A. and Conlon, G. (2003), 'Does it Pay to Attend a Prestigious University?', Centre for the Economics of Education (CEE) Discussion Paper number 33. Accessed $18^{\text {th }}$ October 2012 from http://cee.lse.ac.uk/ceedps/ceedp22.pdf

Chowdry, H., Crawford, C., Dearden, L., Goodman, A. and Vignoles, A. (2012) 'Widening Participation in Higher Education: Analysis Using Linked Administrative Data', Journal of the Royal Statistical Society Series A, doi: 10.1111/j.1467-985X.2012.01043.x.

Cunha, F., Heckman, J. and Lochner, L. (2006) 'Interpreting the Evidence on Life Cycle Skill Formation'. In Eric Hanushek and Finis Welch (eds) Handbook of the Economics of Education, Amsterdam: Holland North.

Duncan, G. and Murnane, R. (2012) Whither Opportunity: Rising Inequality, Schools, and Children's Life Changes. New York: Russell Sage Foundation.

Ermisch, J. and Del Bono, E. (2012) 'Inequality in Achievements during Adolescence' in J. Ermisch, M. Jantti and T. Smeeding (eds) Inequality from Childhood to Adulthood: A CrossNational Perspective on the Transmission of Advantage, New York: Russell Sage Foundation. 
Ermisch, J., Jantti, M. and Smeeding, T. (2012) Inequality from Childhood to Adulthood: A Cross-National Perspective on the Transmission of Advantage, New York: Russell Sage Foundation

Finnie, R. and Mueller, R. (2008) 'The Effects of Family Income, Parental Education and Other Background Factors on Access to Post-Secondary Education in Canada: Evidence from the YITS', MESA Research Paper 2008-2. Accessed 25 ${ }^{\text {th }}$ October 2012 from http://higheredstrategy.com/mesa/pub/pdf/MESA_Finnie_Mueller.pdf

Finnie, R. (2012) 'Access to Post-Secondary Education: The Importance of Family Culture', Children and Youth Service Review, 34(6): 1161-1170.

Groot, W. and van den Brink,H. (2006) 'What Does Education Do To Our Health?' Measuring the Effects of Education on Health and Civic Engagement: Proceedings of the Copenhagen Symposium. Accessed 16/01/2014 from http://www.oecd.org/edu/innovationeducation/37425763.pdf

Haveman, R. and Wolfe, B. (1995) 'The Determinants of Children's Attainments: A Review of Methods and Findings.' Journal of Economic Literature 33(4): 1829-1878.

Hoekstra, M. (2009) 'The Effect of Attending the Flagship State University on Earnings: A Discontinuity-Based Approach', The Review of Economics and Statistics, Volume 91 (4): 717 $-724$.

Ingels, S., Pratt, D., Rogers, J., Siegel, P. and Stutts, E. (2005) 'Education Longitudinal Study of 2002: Base-year to First Follow-up Data file Documentation', US Department of Education. Washington, DC: National Center for Education Statistics.

Inoue, A. and Solon, G. (2010) 'Two-Sample Instrumental Variables Estimators', The Review of Economics and Statistics, 92(3): 557-561.

Jackson, M., Erikson, R. Goldthorpe, J. and Yaish, M. (2007) 'Primary and Secondary Effects in Class Differentials in Educational Attainment: The Transition to A-level Courses in England and Wales', Acta Sociologica, 50(3): 211-229.

Jackson, M. 2013. Determined to Succeed Performance versus Choice in Educational Attainment. Stanford: Stanford University Press.

Jerrim, J. 2013. 'The Reliability of Trends over Time in International Education Test Scores: Is the Performance of England's Secondary School Pupils Really in Relative Decline?' Journal of Social Policy 42(2): 259-79.

Le, A. and Miller, P. (2005) 'Participation in Higher Education: Equity and Access', The Economic Record, 81(253): 152 - 165.

Long, B. and Kurlaender, M. (2009) 'Do Community Colleges Provide a Viable Pathway to a Baccalaureate Degree?’, Educational Evaluation and Policy Analysis, 31(1): 30 - 53.

Oscar Marcenaro-Gutierrez, O.; Galindo-Rueda, F. and Vignoles, A. 2006. 'Who Actually Goes to University?' Empirical Economics 32(2-3): 333-57. 
Micklewright, J. and Schnepf, S. (2006) 'Response Bias in England in PISA 2000 and 2003', Department for Education and Skills Research Report 771. Accessed $18^{\text {th }}$ October 2012 from www.education.gov.uk/publications/eOrderingDownload/RR771.pdf.

Micklewright, J., Schnepf, S. and Skinner, C. (2010) 'Non-response Biases in Surveys of School Children: The Case of the English PISA Samples', DoQSS working paper. Access $26^{\text {th }}$ November 2012 from http://ideas.repec.org/p/qss/dqsswp/1004.html.

Micklewright, J., Schnepf, S. and Skinner, C. (2012) 'Non-response Biases in Surveys of School Children: The Case of the English PISA Samples', Journal of the Royal Statistical Society Series A, 175(4): 915 - 938.

OECD (2008) 'Education at a Glance 2008: OECD indicators', OECD: Paris.

OECD (2009) 'PISA Data Analysis Manual: SPSS Second Edition', OECD: Paris.

OECD (2012) 'Education at a Glance 2012: OECD Indicators’, OECD: Paris.

O'Leary, N. and Sloane, P. (2005) 'The Return to a University Education in Great Britain', National Institute Economic Review, 193(3): 75 - 89.

Powdthavee, N. and Vignoles, A. (2009), 'The Socioeconomic Gap in University Dropouts', The B.E. Journal of Economic Analysis \& Policy, 9(1): article 19.

Smeeding, T. Erikson, R. and Jantti, M. (2011) Persistence, Privilege and Parenting: The Comparative Study of Intergenerational Mobility, New York: Russell Sage Foundation. 
Table 1. Higher education across Anglophone countries

\begin{tabular}{|c|c|c|c|c|c|}
\hline & Source & $\mathbf{U S}$ & England & Canada & Australia \\
\hline \multicolumn{6}{|l|}{ Educational expenditure } \\
\hline$\%$ of GDP spent on tertiary education & OECD (EAG 2012) & 1.3 & 0.8 & 1.8 & 1.1 \\
\hline \multicolumn{6}{|l|}{ Bachelor's degree Enrolment } \\
\hline$\%$ of population starting bachelor's degree by age 20 & Youth panel & 45 & 37 & 43 & 39 \\
\hline$\%$ of population obtaining bachelor's degree (all ages) & OECD (EAG 2012) & 50 & 48 & 36 & 38 \\
\hline Non-completion rate (\% of entrants) & OECD (EAG 2008) & 44 & 21 & $25^{+}$ & 28 \\
\hline$\%$ of enrolments by foreign students & OECD (EAG 2012) & 3 & 18 & 7 & 22 \\
\hline$\%$ tertiary students rolled in private universities & OECD (EAG 2012) & 32 & 0 & 0 & 3 \\
\hline \multicolumn{6}{|l|}{ University tuition fees } \\
\hline Average annual tuition fees public institutions (\$US) & OECD (EAG 2012) & 6,312 & $4,731 *$ & 3,774 & 4,222 \\
\hline Average annual tuition fees private institutions (\$US) & OECD (EAG 2012) & 22,852 & - & - & 9,112 \\
\hline Average tuition fee all students (\$US) & Author calculation & 11,605 & $4,731 *$ & 3,774 & 4,369 \\
\hline Average length of bachelor's degree course (years) & & 4 & 3 & $3-4^{\wedge}$ & $3-4^{\wedge}$ \\
\hline Tuition cost of a bachelor's degree (\$US) & Author calculation & 46,419 & 14,193 & 15,096 & 17,475 \\
\hline \multicolumn{6}{|l|}{ University scholarships } \\
\hline$\%$ of pupils receiving grant / scholarship & OECD (EAG 2012) & 65 & 58 & - & \\
\hline$\%$ of pupils receiving public loans & OECD (EAG 2012) & 50 & 87 & - & 81 \\
\hline$\%$ NOT receiving loan, scholarship or grant & OECD (EAG 2012) & 24 & 6 & - & 19 \\
\hline
\end{tabular}

Notes:

1'Youth panel' refers to estimates based upon the datasets analysed in this paper. 'Author calculation' refers to our own calculations using information from Education at a Glance data.

2 EAG stands for Education at a Glance and is followed by the relevant publication year. 3 Tuition costs have been converted into US dollars by the OECD using purchasing power parity.

$4 *$ Figures refer to pre September 2012.

$5+$ Refers to Québec only.

$6^{\wedge}$ Degree length varies by subject in Canada and honors degrees are 4 years in Australia. 
Table 2. Descriptive statistics

\begin{tabular}{lcccc}
\hline & United States & England & Canada & Australia \\
\hline \% Male & 50 & 49 & 50 & 51 \\
\% non-native language & 4 & 6 & 8 & 9 \\
\% Low education (ISCED 0 - 2) & 7 & 12 & 7 & 13 \\
\% Medium education (ISCED 3 - 5b) & 56 & 68 & 64 & 47 \\
\% High education (ISCED 5a+) & 38 & 20 & 29 & 40 \\
\% university & 45 & 37 & 43 & 39 \\
\% low parental education entering university & 20 & 20 & 12 & 26 \\
\% middle parental education entering university & 36 & 31 & 32 & 33 \\
\% high parental education entering university & 69 & 69 & 64 & 60 \\
\hline $\mathbf{n}$ & $\mathbf{1 2 , 5 7 5}$ & $\mathbf{7 , 7 1 5}$ & $\mathbf{9 , 4 4 6}$ & $\mathbf{6 , 5 3 6}$ \\
\hline
\end{tabular}

Notes:

1 Figures refer to column percentages

2 ISCED $0-2$ = Below high school; ISCED 3 - 5B = High school to associates degree;

ISCED 5A /6 = Bachelor's degree or higher. 
Table 3. School achievement grades within the longitudinal datasets

\begin{tabular}{llll}
\hline England & United States & Australia & Canada \\
\hline $\begin{array}{l}\text { Completed age 18 } \\
\text { schooling }\end{array}$ & High school graduate & $\begin{array}{l}\text { High school graduate } \\
\text { Tertiary entry rank } \\
\text { quintile }\end{array}$ & $\begin{array}{l}\text { High school } \\
\text { graduate }\end{array}$ \\
$\begin{array}{l}\text { A* - GCSE maths } \\
\text { A* - C GCSE English }\end{array}$ & $\begin{array}{l}\text { GPA in grade 12 } \\
\text { Carnegie units taken } \\
\text { SAT quintile (or equivalent }\end{array}$ & $\begin{array}{l}\text { GPA high school } \\
\text { GPA maths }\end{array}$ \\
$\begin{array}{l}\text { Key stage 4 total points } \\
\text { Key stage 5 total points }\end{array}$ & ACT) & GPe 18 maths test quintile \\
$\begin{array}{l}\text { A-Level grades and } \\
\text { equaivalents }\end{array}$ & & & \\
\hline
\end{tabular}


Figure 1. A framework of intergenerational persistence

STAGE 1 (Childhood investments)

STAGE 2 (HE investment)

STAGE 3 (Labour market entry)

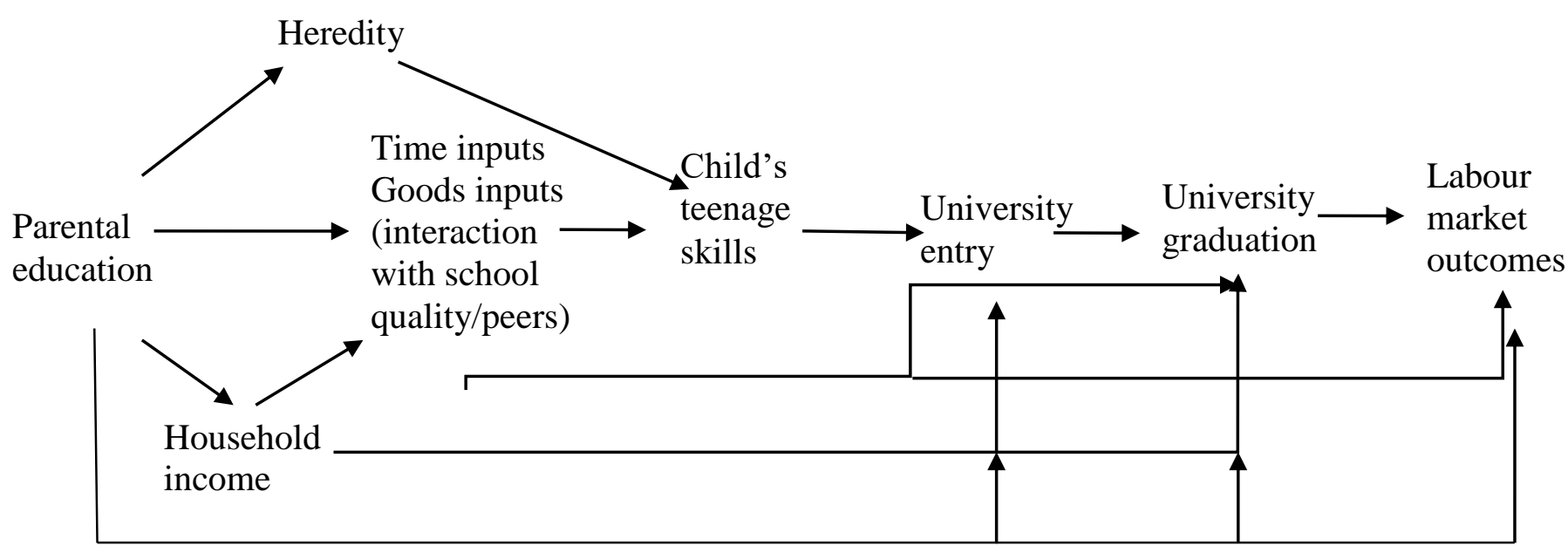

\section{Notes}

1 Source: Adapted from Haveman and Wolfe (1995, figure 1). 
Figure 2. The socio - economic gap in college participation across Anglophone countries

(A) Basic controls only

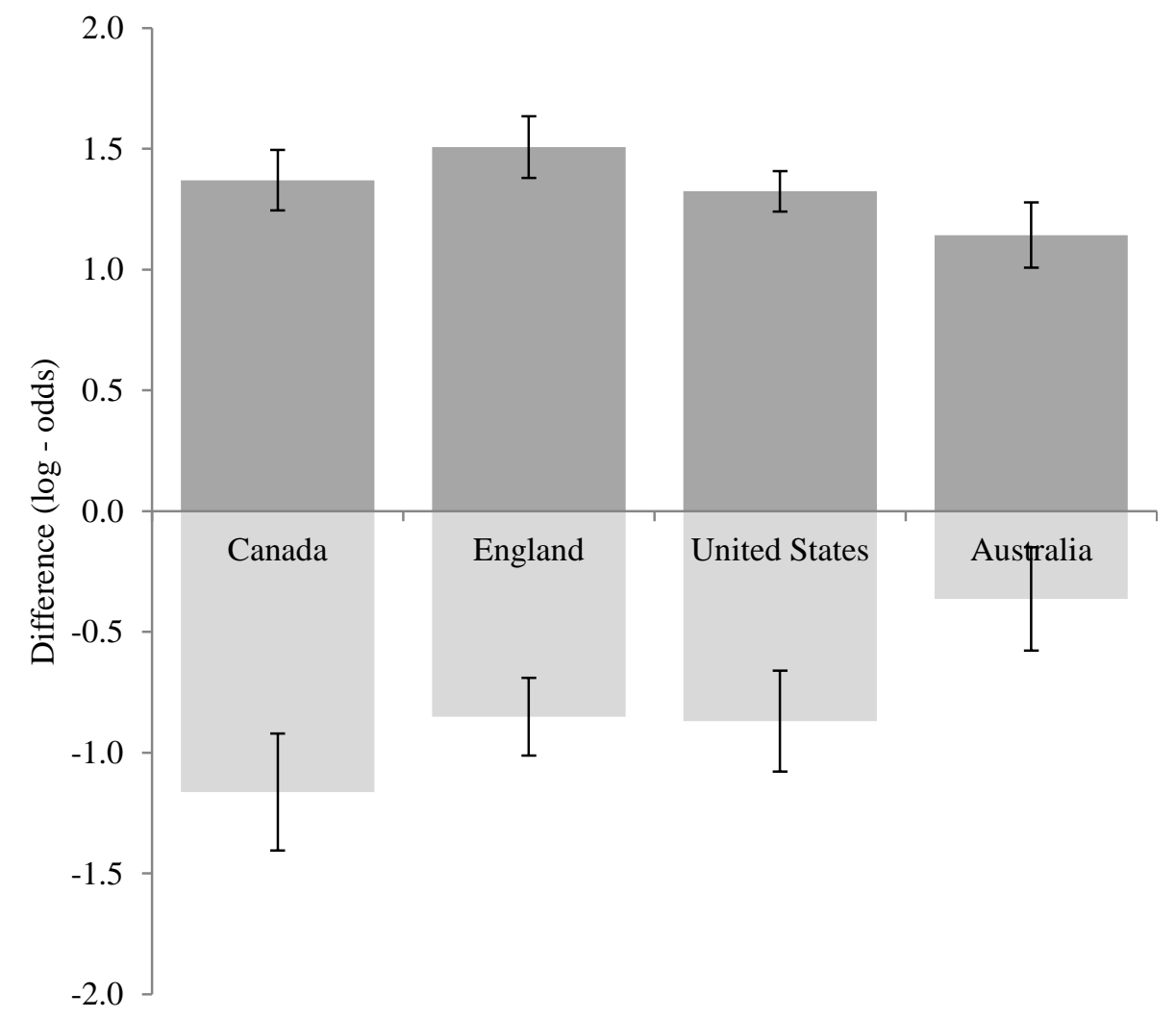

(B) PISA scores at age 15

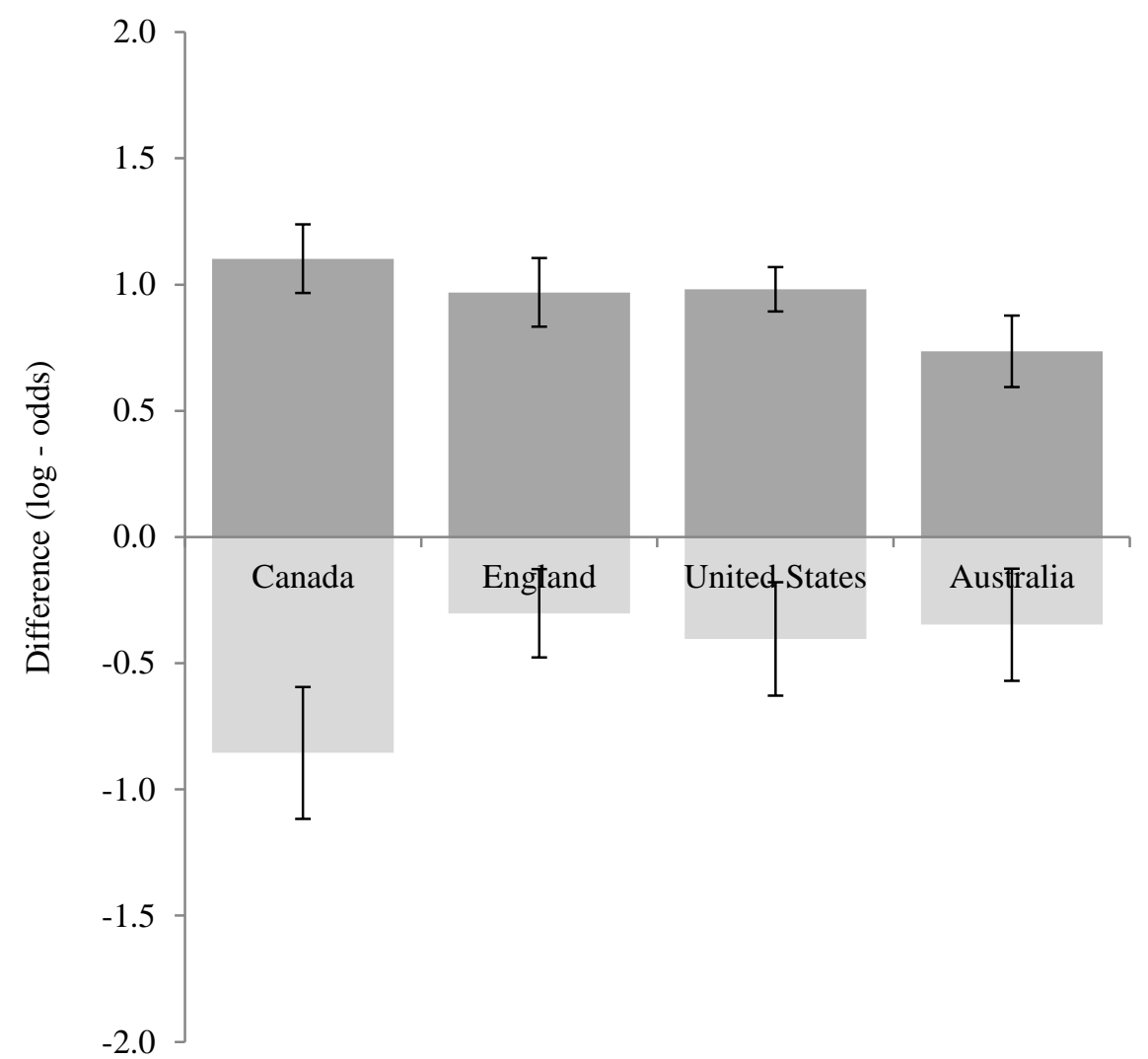

Notes: Figures for England refer to state school pupils only. The light grey segment of the bars illustrates the difference between ISCED 0 - 2 and ISCED 3 $5 \mathrm{~B}$ groups. Dark grey segments refer to the difference between ISCED $3-5 \mathrm{~B}$ and ISCED 5A /6 groups. Thin black lines running through the centre are the estimated $90 \%$ confidence intervals. 
(C) School fixed-effects

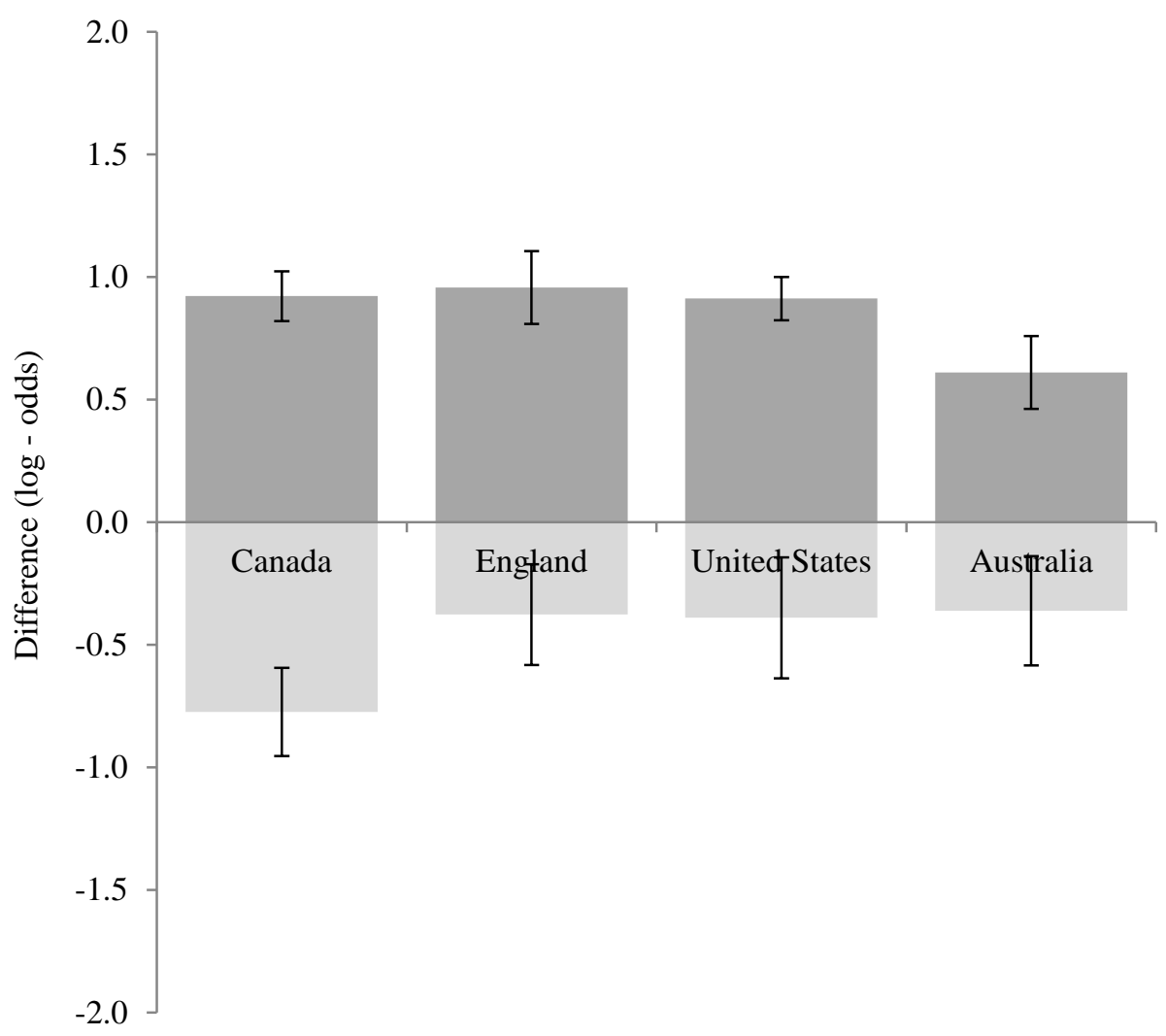

(D) School grades age 18

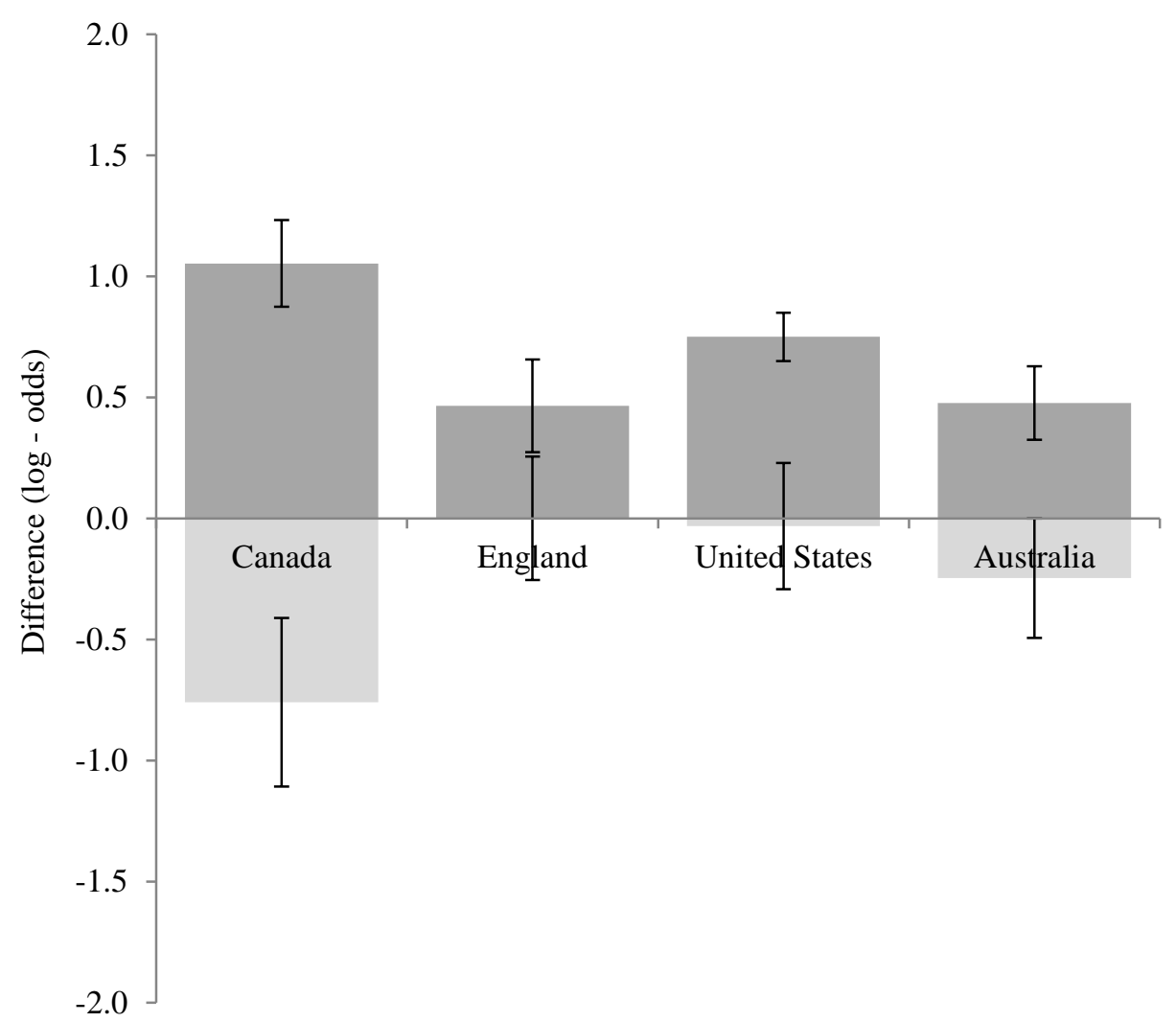

